\title{
Selective encoding from multielement visual displays*
}

\author{
ROBERT L. COLEGATE $\dagger$, JAMES E. HOFFMAN, and CHARLES W. ERIKSEN $\dagger \dagger$ \\ University of Illinois, Champaign, Illinois 61820
}

\begin{abstract}
When a multiletter display is preceded by a bar designating one of the letters for report, reaction time (RT) to voice the indicated letter decreases. Previous research had indicated that the efficiency of this selective mechanism decreases as the number of display elements increases. Two experiments were conducted to determine whether the effect of display size could be eliminated when the indicator precedes the display at long intervals. Results indicated that the display size effect was maintained. The results could not be at tributed to eye movements, but were interpreted in terms of a central encoding mechanism that is limited in its precision of localization and exclusion.
\end{abstract}

At the phenomenal level, we can look at an object and see it as an entire object without concentrating on specific details. For example, we may look at the clock on the wall, even noticing what time it is, but not paying "attention" to specific characteristics of the numerals. Or we can phenomenally direct our attention to one of the numerals on the clock such as the 3 and in the process seem to exclude the details of the other numerals. This experience can occur even though our distance from the clock is such that the whole clock face is falling within the fovea and assuring adequate resolution of detail for all parts of the clock. It is as though we had a limited capacity for processing information per unit of time, and we can select which information and in what order it is going to be processed and encoded.

We have been employing an experimental analog of this phenomenal experience. Circular displays of a small subset of letters are presented to Ss with a black bar indicator designating one of the letters in the display. The display as a whole is foveal, subtending approximately 2 deg of visual angle on the diameter. The bar indicator is quite conspicuous, both in terms of its size and shape, but primarily in terms of its location as an extension of an imaginary radius from the center of the display extending beyond the circumference of the imaginary circle along which the letters are arrayed. Ss are instructed to name the designated or target letter as quickly as possible. By manipulating the display variables, we have hoped to delineate some of the characteristics by which selective attention or encoding occurs.

In a previous experiment (Eriksen \& Hoffman, 1972a), we found that time to name the indicated or target letter decreased if the bar indicator was presented

\footnotetext{
*This investigation was supported by U.S. Public Health Service Research Grant MH-1206, U.S. Public Health Service Research Career Award K6-MH-22014, and Predoctoral Fellowship 1-F01-MH-47201-01.

$\div$ Now with the Department of Psychology. Norfolk State College. Norfolk. Virginia 23504.

$\div \div$ Requests for reprints should be made to Professor Charles II. Eriksen. Psychology Building. University of Illinois, Champaign. Illinois 61820 .
}

$150 \mathrm{msec}$ before the display so that the $\mathrm{S}$ knew where the target letter would occur. There are several reasons why this result might be expected. Obviously, location and perception of the indicator does not occur in zero time. S cannot begin to voice the target letter until he has processed the information telling him which target letter to voice. Thus, reaction time (RT), plotted as a function of the stimulus onset asynchrony (SOA) by which the indicator precedes the display, would be expected to decrease until the SOA was long enough to encompass the longest latency for processing or perceiving the indicator.

It is also possible that, after the indicator has been perceived, some time is required to make the position selection, i.e., to focus attention on the specific element to be reported. However, recent findings (Eriksen \& Hoffman, 1972b) seem to rule out a selective or attention focusing process distributed over time.

Both number of noise elements in the display and their spacing relative to the target letter have been found to influence processing of the target (Eriksen \& Rohrbaugh, 1970; Eriksen \& Hoffman, 1972a). The physical spacing between adjacent elements has an effect primarily when the noise elements are within $1 \mathrm{deg}$ of angle or less of the target letter (Eriksen \& Hoffman, 1972 b). Spacing between elements beyond this distance from the target appears to be immaterial.

There are several ways in which the number of noise elements could affect RT to the target letter independent of spacing. One possibility is that with a greater number of elements in the display, there are a greater number of display positions. Thus, when the indicator occurs, more information is conveyed in a 12-element display than is conveyed in a 4 - or an 8-element display. If the time required to process the indicator is proportional to the amount of information contained in its occurrence, then an indicator for a 12-element display would require more time to process than would an indicator for a display with fewer elements.

It is also possible that, with a greater number of noise elements, it is more difficult to discriminate or locate the indicator. Estes and his colleagues (Estes \& Taylor. 1966: Estes \& Wessel, 1966) have shown on a search task 
that the time required to locate target elements increases with an increase in the number of noise elements in the display. Estes (1972) points out that, with an increase in the number of noise elements, there is an increased possibility of confusion between targets and noise or the discrimination of targets from noise becomes more difficult. Indeed, Estes finds that if rectangles are used as noise elements instead of other letters, the effect due to increasing the number of noise elements is greatly attenuated, a result compatible with the findings of McIntyre, Fox, and Neale (1970).

However, in our experimental arrangement, it seems unlikely that confusions between the bar marker and the noise elements in the display could account for the effects of display size. Not only is there a marked dissimilarity between the bar marker and alphabet letters (comparable to the difference in Estes's rectangles and letters), but also the bar marker enjoys a spatially unique position. It always occurs external to the circular arrangement of display letters.

There is, though, another way in which the number of noise elements could affect the processing time of the indicator. When the indicator occurs simultaneously with the display or in close temporal proximity, the presence of the additional elements in the visual field could drain off processing energy or compete for processing units such as feature analyzers that would otherwise be available for the processing of the indicator itself. Thus, the processing of the indicator might be slowed if the S also processed, at least to some level, the elements that occurred along with the indicator.

There also is the possibility that the number of noise elements has no effect upon the location and processing of the indicator. Instead, the increased RT in voicing the target might be attributed to the fact that the noise elements appear with the target letter and the target letter itself is delayed in processing due to the competing stimuli being present. This position essentially says that the precision of selective encoding is spatially limited. Even though $S$ knows the position to be reported beforehand, the effect of extraneous elements cannot be completely eliminated.

The present experiment is an attempt to determine the locus of the effect of number of noise elements. Specifically, we wished to determine if the noise elements were affecting the location or processing of the indicator, the processing of the target, or both. Eightand 12-element displays were employed with an indicator that occurred either simultaneously with the display or preceded the display by SOAs as long as $250 \mathrm{msec}$. On the basis of previous research (Potter \& Levy, 1969; Eriksen \& Eriksen, 1972), 250 msec should provide sufficient time to locate and process the indicator before the noise elements occur. If the effect of number of display elements is solely attributable to reducing the discriminability of the indicator or increasing its processing time, RT differences between 8and 12-element displays should disappear as the SOA by which the indicator precedes the display is increased. The RT-SOA function for both display sizes should approach the same asymptote.

If the number of elements in the display have their primary effect on processing the target letter, increasing the SOA by which the indicator precedes the display would have little or no effect, since the noise letters appear with the target letter and compete for processing units or processing energy at the time the target letter is to be processed. Thus, 8- and 12-letter displays would have different asymptotic RT values on the RT-SOA function.

Since the two above possibilities are not mutually exclusive, the experiment could reveal that both effects are operating. Under this circumstance, the RT difference between 8 - and 12-element displays would be greatest at $\mathrm{SOA}=0$ and the difference would decrease as the SOA by which the indicator preceded the display increased. The difference in RT between 8-and 12-size displays at asymptote on the RT-SOA function would reflect the interference of noise letters on the processing of the target, and the difference in RT at SOA $=0$ would reflect not only this interference, but also the interference of the noise letters on locating and/or processing the indicator (Eriksen \& Hoffman, 1972b).

\section{EXPERIMENT I}

\section{Method}

\section{Subjects}

Two male and two female students at the University of Illinois served as paid Ss. All had normal or corrected-to-normal vision.

\section{Apparatus and Stimuli}

The stimuli were displayed with a Scientific Prototype Model G-A three-field tachistoscope, which had been modified by replacing the manufacturer's bulbs with Sylvania F4T 5/CWX fluorescent lamps. All fields were set at $6 \mathrm{~mL}$. A black fixation cross, $.6 \mathrm{deg}$ of visual angle and mounted on a white vinyl card, appeared in the adaptation fjeld, which remained on except when one of the other fields was activated. Trials were initiated by $S$ closing a switch which triggered the tachistoscope and a Hunter Model 120A Klockounter. Voice RT was recorded in milliseconds.

For the 8-letter displays, 12 different displays were constructed by using the capital letters $A, M, H$, and $U$ twice each to fill the eight positions on each display card. The 12,3,6, and 9 o'clock positions and the four intermediate positions were used. The arrangement of the letters in the circular array was constrained such that the same letter could not appear in adjacent positions, and the letter-position combinations occurred equally often. The black letters were obtained from Para-tipe No. 11316 and were mounted on white vinyl cards. Each letter subtended $.2 \mathrm{deg}$ of visual angle. The letters were equally spaced on an imaginary circle, $2 \mathrm{deg}$ of visual angle in diam.

For the 12-letter displays, a second set of 12 cards was constructed in the same manner involved in the 8-letter displays. Here, each letter was used three times to fill the 12 clock positions on each card.

Indicators consisted of black lines, $.5 \mathrm{deg}$ of angle long and $1 \mathrm{deg}$ of angle wide, mounted on clear plastic cards. Each 
indicator was located with reference to the center of the display on an imaginary ray extending beyond the designated letter position, with the nearest end .3 deg from the letter. A black dot, . 22 deg of visual angle, appeared on each plastic card along with the indicator and was located at a point corresponding to the center of the display. Two different sets of indicator cards were constructed, one for each of the two display sizes. For control conditions, a single clear plastic card with a dot appearing in the center was constructed. Both the indicators and the control dot cards were presented over a white vinyl card similar to that used for mounting the display, and they appeared in Field 1 in the tachistoscope.

\section{Procedure}

Each of the four Ss was run under all experimental conditions, which consisted of the two display sizes, 8 and 12 letters, preceded by an indicator at SOAs of $250,150,100,50$, and $0 \mathrm{msec}$. In addition to the leading indicator condition. a control condition was also employed for both display sizes. Since RT to a second signal (display) might be affected by the preceding signal (indicator), a control for the effect of a preceding signal was necessary. This "warning" control consisted of presenting a black dot in the center of the field, but without the indicator line at each of the SOAs used for the indicator. On these trials, the indicator appeared simultaneously with the display. Since the dot occurred in what would be the center of the display, it provided no information as to the target-letter location. In the indicator condition, when the indicator preceded the display, it remained on until the display was presented for $1 \mathrm{sec}$.

Prior to the experimental sessions, Ss were given two 50-min sessions of practice, during which they had at least 12 trials under each condition. During these practice sessions, Ss were told their RT after every trial. Following practice, eight experimental sessions were run. Over each two sessions, one block of 12 trials was run in each of the leading indicator and warning conditions for each display size. One block of the simultaneous conditions was run for each display size during every session. The order of display size by warning or indicator conditions was counterbalanced within display sizes and Ss over sessions. Each position and each letter was indicated equally often within each condition.

Experimental sessions were preceded by $5 \mathrm{~min}$ of dark adaptation and one block of warm-up trials with simultaneous indicator and the display size the $S$ was to see during the first half of that session. S was told his RT after each warm-up trial. For the experimental trials. the only feedback given was to tell $S$ the range of his RTs at the end of each block of trials. S was instructed to respond accurately, rapidly, and distinctly. A 5-min rest period was given midway through the session. Over the experimental conditions, error rates varied between Ss from a low of $.6 \%$ to a high of $2.9 \%$, with an average of $2 \%$. Within this low error rate, no trends toward differential errors under the different experimental conditions and SOAs was observed.

\section{Results}

In Fig. 1, the mean RT in voicing the target letter is shown as a function of the SOA between the onset of the warning dot or the indicator for each of the two display sizes. A four-way analysis of variance (display sizes, leading indicator and warning conditions, SOA, and $\mathrm{Ss}$ ) showed all four main effects to be significant well beyond the .001 level. In addition, the interaction between SOA and the leading indicator and warning conditions was significant $(\mathrm{p}<.01)$, as was also the interaction between SOA. conditions, and display sizes $(\mathrm{p}<.05)$.

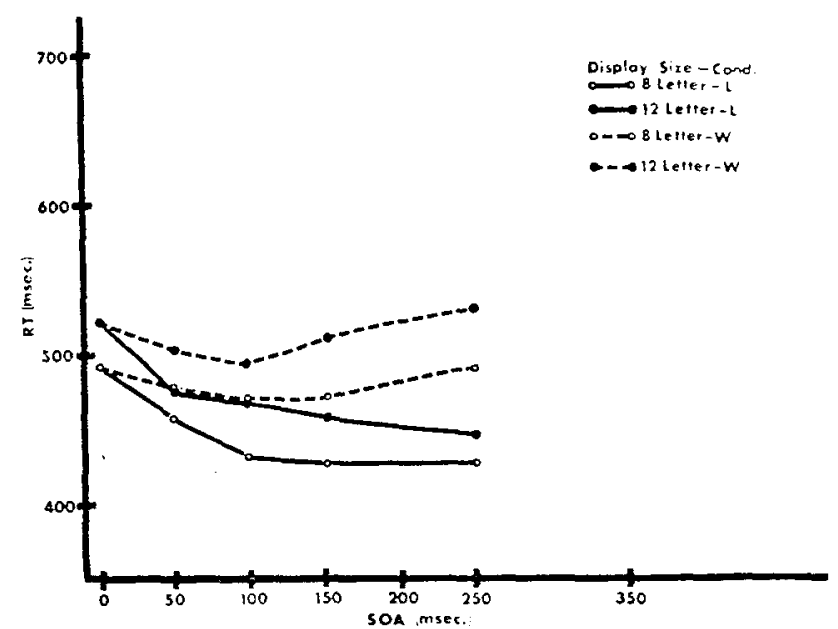

Fig. 1. Mean RT as a function of SOA for 8- and 12-letter displays under the warning (W) and leading indicator (L) conditions.

The importance of a control for the effect a leading indicator might have as a possible warning signal is apparent in Fig. 1. For both 8- and 12-letter displays, RT to the target letter was less if the display with a simultaneous indicator was preceded by the informationless dot by intervals as long as $150 \mathrm{msec}$. The maximum reduction in RT (20-25 msec) occurred when this dot preceded the display by $100 \mathrm{msec}$ for both 8 . and 12 -letter display sizes.

The effect of the leading indicator was found to be quite prominent over and above that of the warning control. For the 8-letter displays, there was a progressive and marked reduction in $\mathrm{RT}$ as the indicator preceded the display by longer intervals out to $150 \mathrm{msec}$. By this SOA, the function appears to have become asymptotic. A very similar effect was obtained for the 12-letter displays, although for this display size, an asymptote at an SOA of $150 \mathrm{msec}$ is not clearly defined.

The effect of display size is quite apparent in both the warning control and leading indicator conditions. At SOA $=0$, RT to the target letter was $31 \mathrm{msec}$ faster for the 8-letter display in the indicator condition and $28 \mathrm{msec}$ faster in the warning condition. Throughout the range of SOAs to $150 \mathrm{msec}$, the RT difference between the two display sizes stayed within approximately this range. There is a suggestion, however, that the 12-letter display may be approaching the same asymptotic RT level as the 8-letter display, since the function for the 12-letter display appears to be still declining at an SOA of $250 \mathrm{msec}$. An analysis of variance on the data for only the indicating condition, though, does not yield a significant interaction between display size and the SOA by which the indicator preceded the display $(p>.05)$.

\section{Discussion}

The present results replicate in a highly satisfactory manner our previous findings with respect to the effects 
of display size and the facilitating effect of a leading indicator. Further, the evidence provided by the warning dot control condition makes it quite clear that the decrease in RT that accompanies the leading indicator cannot be attributed to a first signal effect upon RT to a following signal. Although the warning control does show an effect upon RT, the shape of the function is quite dissimilar to that obtained with the leading indicator and the magnitude of the effect is much smaller.

Bertelson (1967) and Posner and Boies (1971) have shown that $\mathrm{RT}$ is reduced if a warning signal precedes the signal to respond by an interval of some $200-500 \mathrm{msec}$. In the present study, the maximum facilitation of the warning signal occurred when it preceded the display by $100 \mathrm{msec}$, an interval appreciably shorter than that previously found. However, it is possible that the true warning signal operating in the present experiment is not the informationless dot that precedes the display, but some cue internal to $S$. Since $S$ initiated each trial by pressing a microswitch, the true warning signal may consist of some internal process associated with his decision to initiate the trial. If this is the case, then the actual interval between this warning signal and the maximum facilitation in $\mathbf{R T}$ is indeterminant in the present experimental arrangement. However, the warning control condition appearing at various intervals before the display has the capacity to reflect any overall warning effect upon RT.

The major interest in the present results concerns the shape of the RT-SOA function for the two display sizes. If we accept the results as showing that the asymptotic RT value is longer for the 12-letter display than for the 8-letter display and that the relative difference is approximately the same value as obtained when the indicator is simultaneous with the display occurrence, then certain conclusions follow. The number of elements in a display does not act by impairing the location or processing of the indicator, but rather by interfering with or slowing down the processing of the target letter after the location information has been processed.

The argument to support such a conclusion would run as follows. When the indicator precedes the display by an SOA of $250 \mathrm{msec}$, the S has had time to process the indicator without any disturbing stimuli in the visual field. There are no noise elements present to impede the location of the indicator or to compete for the processing capacity required by the indicator during this interval of time. The finding that a target letter embedded in a 12-element letter display produces longer voicing latencies after $250 \mathrm{msec}$ of a leading indicator would point the locus of the effect to the onset of the noise letters concurrently with the target letter. This would suggest that the noise letters are either competing for processing units with the target letter or that the limited energy for processing has to be distributed in part over these noise elements.
In search tasks where $S$ is required to find a target letter embedded in a matrix of other letters, search time has also been found to be a direct function of the number of noise elements in the matrix (Estes \& Wessel, 1966). Eriksen and Spencer (1969) found that the effect of noise letters could be attributed to the increased possibility they afforded for confusions with the target letters. Estes (1972) and Bjork and Estes (1971) have obtained collaborating evidence on this point. However, it is apparent from the present data that the number of noise elements is making a contribution over and above that attributable to confusion errors with the target. In the present experimental arrangement, there is little or no possibility of the S's confusing one letter with another. His task is to voice the letter in the already-designated location. Our finding that the number of noise elements still significantly affects RT under these circumstances would implicate some other processes. In addition to the possibility for confusion that exists in the search task, the present findings would suggest that the number of noise elements is also contributing by either draining processing energy away from the S's primary task or by competing and utilizing available processing units such as feature analyzers.

This conclusion implies that a selective attention process is not completely effective in excluding the effect of nonattended stimuli. For the noise elements to impair or interfere with the S's voicing of the target letter, they would have to be achieving some level of processing. At the level of phenomenal report, this seems quite clear, as reflected in the ability of our Ss to tell us things about the display other than the target letter in experiments where the display is presented at brief tachistoscopic durations. Ss would seldom have difficulty in reporting whether a 4- or 8- or 12-element display had been presented, even though they were reporting or identifying only the target letter.

\section{EXPERIMENT II}

In this experiment, 8- and 12-letter displays again were used with simultaneous and preceding indicators. Here, however, the SOA by which the indicator preceded the display was extended to $350 \mathrm{msec}$ and the SOA range from 150 to $350 \mathrm{msec}$ was sampled at $50-\mathrm{msec}$ increments. By increasing the length of the SOA, we hoped to establish more certainly that the asymptotic RT values for 12- and 8-letter displays were indeed different.

To eliminate any possible effect attributable to the positional uncertainty of the indicators between 12 . and 8-letter displays, indicators appeared only at positions corresponding to $12,3,6$, and 9 o'clock. Thus, for both 12- and 8-letter displays, the target letters occurred only in these four possible positions.

This experiment also took a look at the role of eye movements in this experimental paradigm. Previous research (Eriksen \& Rohrbaugh, 1970; Eriksen \& Collins, 


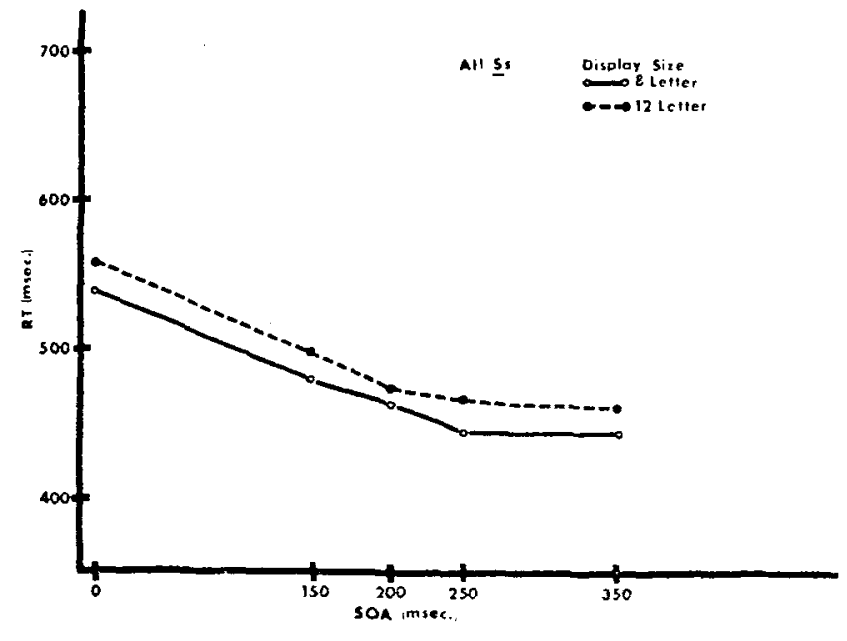

Fig. 2. Mean RT averaged over sessions and Ss as a function of the SOA by which the indicator preceded the display.

1969) had demonstrated that the selective encoding in response to indicators did not require change in foveal fixation. In these experiments, the displays were presented at tachistoscopic durations and identification accuracy of the indicated or target letter was the dependent variable. The evidence was of two kinds. First, the biggest gain in identification accuracy obtained for a leading indicator occurred where the SOA of the indicator and the duration of the visual display together did not equal the normal latency for a voluntary saccadic eye movement. The second line of evidence involved having the $S$ not only report the indicated or target letter, but also the letter diametrically opposite the target letter in the display. If, at the longer SOAs, the $S$ was changing his fixation so as to obtain a more precise or highly resolved image of the target letter in his fovea, this would automatically involve placing a letter diametrically opposite the target in a less sensitive foveal location. Thus, as SOA increased, identification accuracy for the target letter would be expected to increase, but for the letter diametrically opposite, performance should drop. It was found, instead (Eriksen \& Collins, 1969), that both the target letter and the one diametrically opposite improved in identification accuracy with the increasing SOA by which the indicator preceded the display.

In the previous experiment, however, visual displays remained on for a full second, allowing ample time for eye movement. That eye movements were not involved as the selective device in the previous research using tachistoscopic exposures does not rule out the possibility that in the present experimental paradigm the selective encoding is mediated by an eye movement that fixates the target letter in the foveal area having the highest resolving power.

\section{Method}

\section{Subjects}

The four Ss consisted of two female students, who served as paid volunteers, and two of the authors.

\section{Apparatus and Stimudi}

Equipment was the same as in the previous experiment, with the following exceptions. When $S$ initiated a trial by closing a microswitch, this activated an auxiliary timer on the tachistoscope as well as a Hunter Model 1522 digital clock set to display RT in milliseconds. The auxiliary timer provided a 200 -msec interval between switch closure and onset of Field 1, which contained the indicator card. A microphone located below S's viewer triggered the voice key, which stopped the digital clock.

Eye movements were recorded from five Beckman electrodes affixed with Beckman electrode paste in adhesive collars. The electrodes were located above and below the right eye (vertical) and below the left and right temples at eye level (horizontal). A ground electrode was centered on the forehead. The electrode resistances were always less than 5,000 ohms.

The electrodes were input to a Grass Model $79 \mathrm{AC}$ amplifier. The $1 / 2$-amplitude bandpass was $.15-15 \mathrm{~Hz}$. The output of the amplifier was monitored continuously on an oscilloscope and averaged on a Fabritec $1052 \mathrm{H}$ signal averager. Averaging was triggered concurrently with the beginning of the trial, and extended for an epoch of $2,048 \mathrm{msec}$. After each block of 16 trials was run, the average record was printed by means of an $X Y$ plotter.

The stimulus materials and displays were constructed in the same manner as in Experiment I. Since, for both the 8- and 12-letter displays, target letters could appear in only four possible positions (those corresponding to $12,3,6$, and 9 o'clock), only four indicator cards were required for both display size conditions.

\section{Procedure}

Each $S$ was given two preliminary $2-h$ sessions devoted to establishing a baseline for the monitoring of eye movements in the main phase of the experiment. He was instructed to initiate a trial by pressing a microswitch and then to move his eyes to fixate on a single letter located either $1 \frac{1 / 2}{2}$ or $1 \mathrm{deg}$ of visual angle removed from the central fixation cross. Additional blocks of trials were run where S's task was to maintain fixation. The average records for the eye movement and for the fixation conditions established appropriate baselines for the level of electrophysiological activity picked up by the recording equipment. A comparison of amplitudes of the 1 - and $1 \frac{1 / 2-d e g}{}$ eye-movement records indicated a satisfactory distance relationship (an average of 17 and $27 \mathrm{microV}$. respectively) and established that the 1 -deg eye-movement records were not due to gross movements.

Since vocal responses were to be required in the main phase of the experiment, additional recording was done to assure that the preparatory muscular activity attendant with the voicing of the stimulus would not obscure or mask the electrophysiological activity arising from eye movements. Results indicated a clearly distinguishable eye-movement record when $S$ also had to rapidly name a letter.

Each $S$ served in two practice sessions followed by four experimental sessions. He was given the ready signal and initiated a trial by pressing a microswitch when a fixation cross appeared in good focus. The indicator card designating one of the four positions to be recorded was located in Field 1 . The adaptation field remained on for the duration of Field 1. which onset $200 \mathrm{msec}$ after hand switch closure. The adaptation field was replaced by Field 2. containing the letter display card at stimulus onset asynchronies of $0.150,200,250$. or $350 \mathrm{msec}$. Field 1 remained on until the offset of Field 2. S was instructed to maintain fixation until the designated letter had been named and to voice the letter quickly'. accurately, and clearly.

Each experimental session consisted of 10 blocks of 16 trials each, one block under each of the sOA by display size 

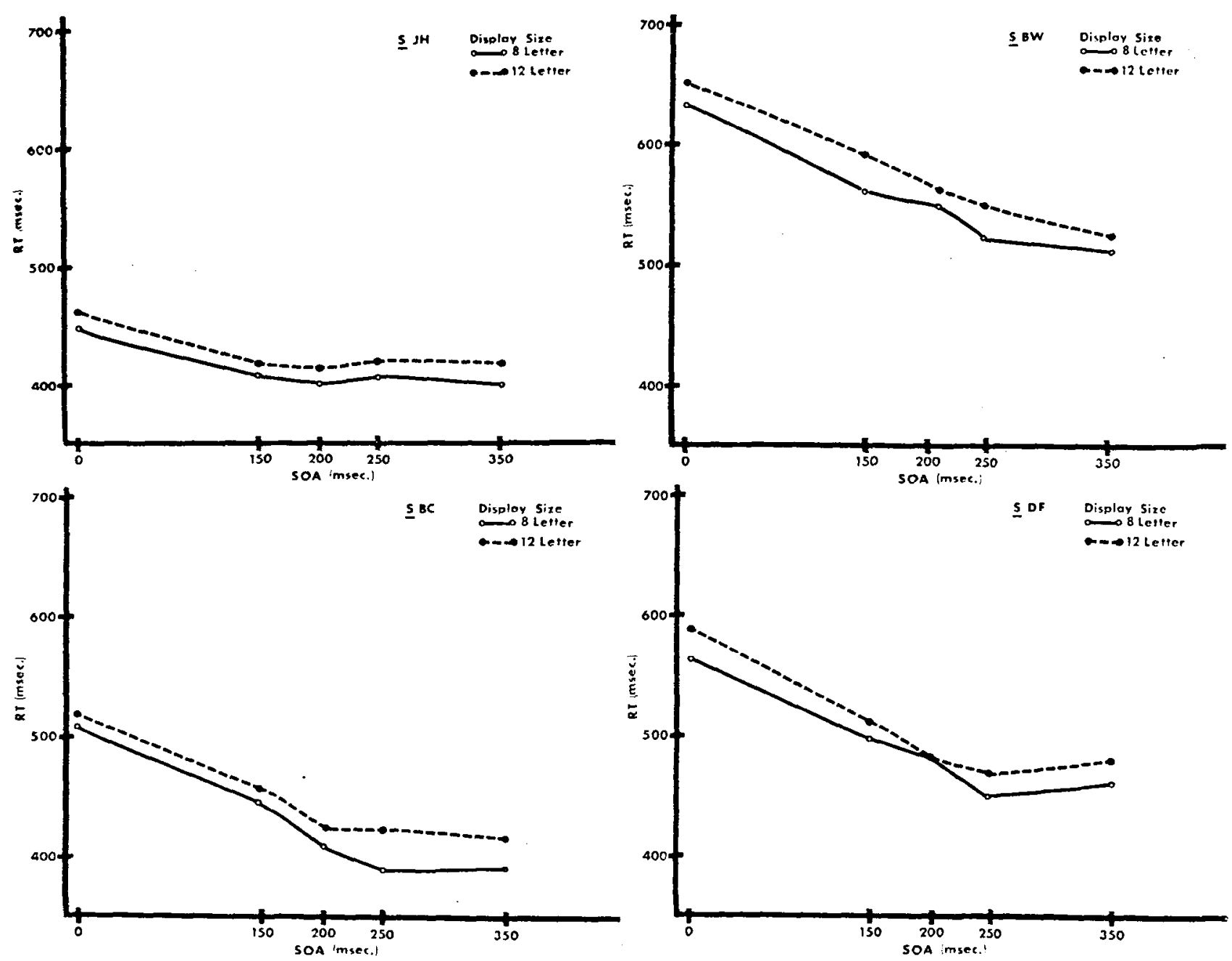

Fig. 3. Mean RT as a function of the SOA of the indicator for each of the four Ss.

combinations. Each block of 16 trials consisted of each of the four letters in each of the four positions in a random order. A block of trials at one SOA by display size combination was followed by a block of trials under the other display size at the same SOA. This order of display size within SOA was the same throughout a session, but alternated over sessions. The alteranting order was counterbalanced across Ss. Eye movements were monitored under each of the SOAs by display size conditions during the first experimental session. Control blocks in which the $S$ simply remained fixated on the cross on each trial were also run. Error rates were low, averaging approximately $2 \%$ over conditions and $\mathrm{Ss}$ and with a range of 1\%-6\%. Error trials were rerun at a later time, providing 64 observations for each condition for each $S$.

\section{Results and Discussion}

Mean RTs computed for each display size condition and averaged over Ss are displayed in Fig. 2. A three-way analysis of variance (Ss, SOA, and display size) was performed on these data. All main effects and interactions were significant at or beyond the .01 level except the following: Ss by Display Size $[F(3,12)=$
$1.18, \mathrm{p}>.25]$ and SOA by Display Size $[\mathrm{F}(4,12)=$ $2.31, p>.101$.

From Figs. 2 and 3, where the RT-SOA functions are shown individually for each of the four Ss, it is seen that our tentative conclusions from Experiment $I$ are supported. That is, 8-and 12-letter display sizes do have a different RT asymptotic value, and the effect of a leading indicator for both display sizes approaches asymptote at essentially the same SOA value. The failure to obtain a significant SOA by Display Size interaction in the analysis of variance is consistent with this conclusion. Only in the case of B.W. is an asymptotic value not clearly defined, and for this $S$ performance is appreciably slower on all aspects of the task than for the other three Ss. For all four Ss, the difference in RT between 8 - and 12-letter displays is essentially of the same magnitude when the indicator is simultaneous as when it precedes the display by $350 \mathrm{msec}$.

Since, for both the 8- and 12-letter displays, there were only four possible positions the indicator could designate, the RT difference between these two display 

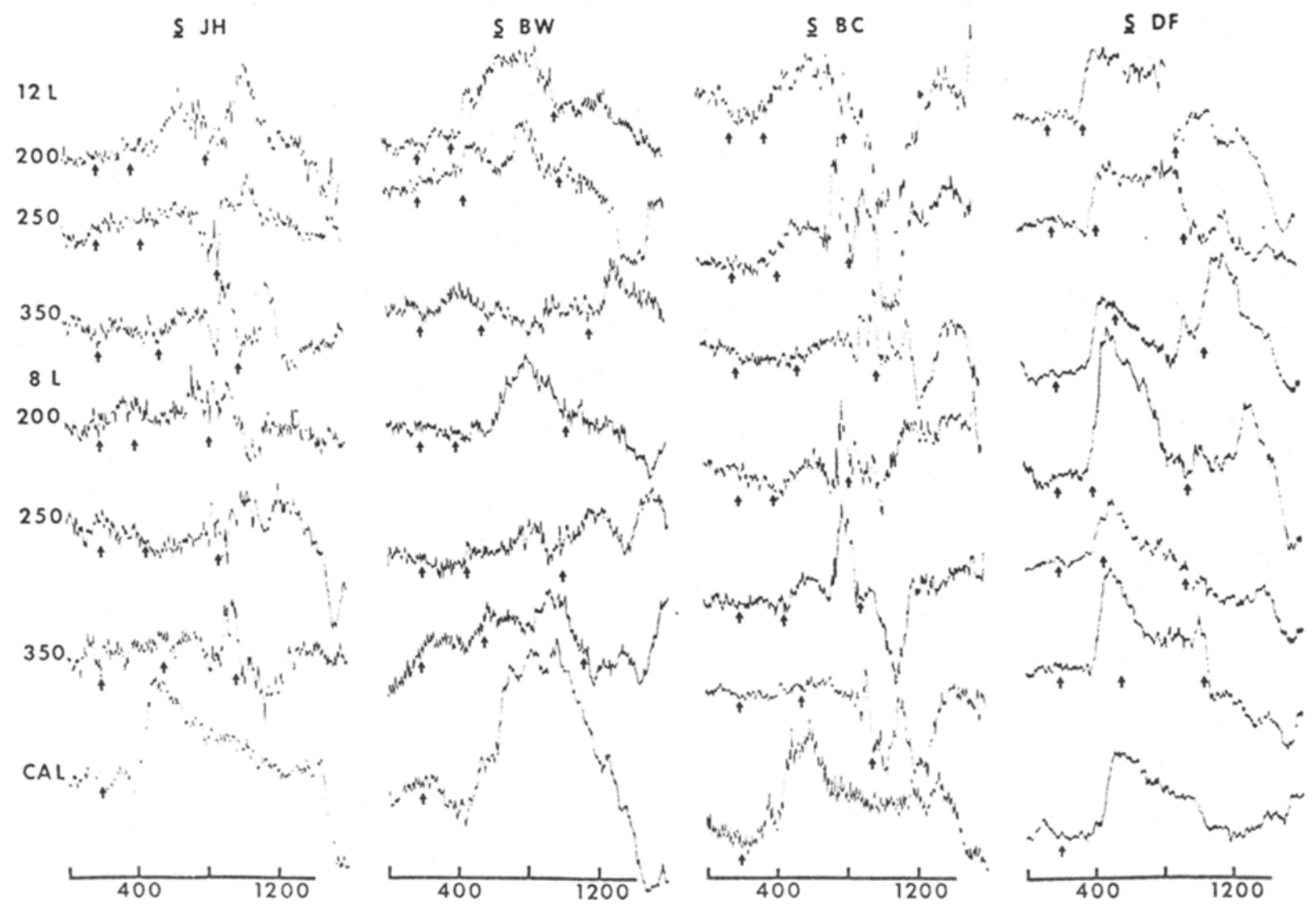

Fig. 4. Eye-movement records for the individual Ss obtained on 8- and 12-letter displays when the indicator preceded the displays by SOAs of 200,250 , and $350 \mathrm{msec}$. The bottom recording for each $S$ is that obtained under instruction to move fixation to a target letter $1 \mathrm{deg}$ of angle removed from the initial fixation. The arrows designate, from left to right, onset of the indicator, onset of the display. and the average latency with which $S$ voiced the target letter.

sizes at all SOA values would not appear to be attributable to differences in processing time for the indicator as a function of its information content. Rather, the effect of number of noise elements is localized at the time of processing of the target letter. This would implicate a process by which the noise elements are either competing with the target letter for available processing energy or employing some of the same analyzing units which would have been used in processing the target letter.

Figure 4 presents the eye-movement data for each $S$ collected during the first experimental session. The data are shown for both 8- and 12-letter displays at SOAs of 200,250 , and $350 \mathrm{msec}$. In addition, calibration data are provided to show what the eye-movement tracing was like when $S$ was directed to change fixation by $1 \mathrm{deg}$. The first arrow on the tracings represents the onset of the indicator, the second the appearance of the display, and the third the average latency at which $S$ voiced the target letter. D.F. reported to $\mathrm{E}$ that she was unable to resist turning her eyes to the target letter, and the tracings obtained from her revealed this. B.W. occasionally had an anticipatory eye movement. but for the other two Ss, eye movements apparently did not occur during the SOA between indicator and the appearance of the display.

In Table 1, voicing latency as a function of SOA is shown for each of the four Ss during the first experimental session where eye-movement recordings were obtained. As is seen, for all Ss there is a rather clear leading indicator effect. Thus, there is no reason to believe that the RT data obtained concurrently with the eye-movement recordings is different in its functional characteristics from the data presented in Fig. 3.

In spite of differences among the Ss in how successful they were in maintaining fixation on the central fixation point, the RT-SOA functions with a leading indicator given in Fig. 3 and Table 1 are quite similar for all Ss. These findings support the conclusion from previous studies (Eriksen \& Rohrbaugh, 1970: Eriksen \& Collins. 1969 ), that a change in foveal fixation is not a necessary antecedent for selective encoding to occur with displays of the size and arrangement that have been employed in our research.

The calibration data in Fig. 3 provide information on the average latency of eye movement when $S$ s are instructed to change fixation from the central fixation cross to a letter when it appears 1 deg out. Summed 
Table 1

Mean RT and $\sigma$ by S and SOA for the 8- and 12-Letter Displays Obtained on the First Session of Experiment II

\begin{tabular}{|c|c|c|c|c|c|c|c|c|c|c|c|}
\hline & \multirow[b]{3}{*}{ Ss } & \multicolumn{10}{|c|}{ SOA } \\
\hline & & \multicolumn{2}{|c|}{0} & \multicolumn{2}{|c|}{150} & \multicolumn{2}{|c|}{200} & \multicolumn{2}{|c|}{250} & \multicolumn{2}{|c|}{350} \\
\hline & & $\overline{\mathbf{x}}$ & $\sigma$ & $\overline{\mathbf{x}}$ & $\sigma$ & $\overline{\mathbf{x}}$ & $\sigma$ & $\overline{\mathrm{x}}$ & $\sigma$ & $\overline{\mathrm{X}}$ & $\sigma$ \\
\hline 12-Letter & $\begin{array}{l}\text { B.C. } \\
\text { D.F. } \\
\text { J.H. } \\
\text { B.W. }\end{array}$ & $\begin{array}{l}567 \\
610 \\
482 \\
635\end{array}$ & $\begin{array}{l}46 \\
60 \\
14 \\
48\end{array}$ & $\begin{array}{l}472 \\
539 \\
452 \\
616\end{array}$ & $\begin{array}{l}29 \\
44 \\
20 \\
44\end{array}$ & $\begin{array}{l}454 \\
532 \\
435 \\
594\end{array}$ & $\begin{array}{l}39 \\
54 \\
28 \\
33\end{array}$ & $\begin{array}{l}434 \\
517 \\
444 \\
569\end{array}$ & $\begin{array}{l}24 \\
67 \\
18 \\
43\end{array}$ & $\begin{array}{l}456 \\
519 \\
459 \\
631\end{array}$ & $\begin{array}{l}67 \\
32 \\
22 \\
74\end{array}$ \\
\hline & $\overline{\mathrm{X}}_{\mathrm{T}}$ & 574 & 42 & 520 & 34 & 504 & 39 & 491 & 38 & 516 & 49 \\
\hline
\end{tabular}

across Ss, the average latency for a change in fixation is on the order of $220 \mathrm{msec}$. In our previous research (Eriksen \& Rohrbaugh, 1970; Eriksen \& Collins, 1969) where we have employed brief $(20-\mathrm{msec})$ tachistoscopic exposures of the visual displays, we have found that the major gain in identification accuracy of the target letter occurs in the first $50-100 \mathrm{msec}$ of lead time for an indicator. For example, if the indicator is presented for $20 \mathrm{msec}$, followed after an interstimulus interval of $100 \mathrm{msec}$ by a 20 -msec presentation of the display, the total elapsed time is $140 \mathrm{msec}$, much too short for the $\mathrm{S}$ to change fixation from the central fixation point to the position of the target letter in the display. This argument, in combination with the current finding that, for two $S s$ at least, selection occurred without eye movement, would seem to require the conclusion that selective encoding of the visual input can occur by a central mechanism that is independent of precise foveal fixation. Such a conclusion, of course, is consistent with the extensive research on attention in dichotic listening tasks (Treisman, 1969).

\section{REFERENCES}

Bertelson, P. The time course of preparation. Quarterly Journal of Experimental Psychology, 1967, 19, 272-279.

Bjork, E. L., \& Estes, W. K. Detection and placement of redundant signal elements in tachistoscopic displays of letters. Perception \& Psychophysics, 1971, 9, 439-442.

Eriksen, C. W., \& Collins, J. F. Temporal course of selective attention. Journal of Experimental Psychology, 1969, 80, 254-261.

Eriksen, C. W., \& Eriksen, B. A. Visual backward masking as measured by voice reaction time. Perception \& Psychophysics, $1972,12,5-8$

Eriksen, C. W., \& Hoffman, J. Some characteristics of selective attention in visual perception determined by vocal reaction time. Perception \& Psychophysics, 1972a, 11, 169-171.

Eriksen, C. W., \& Hoffman, J. Temporal and spatial characteristics of selective encoding from visual displays. Perception \& Psychophysics, 1972b, 12, 201-204.

Eriksen, C. W., \& Rohrbaugh, J. Some factors determining efficiency of selective attention. American Journal of Psychology, 1970, 83, 330-342.

Eriksen, C.W., \& Spencer, T. J. Rate of information processing in visual perception: Some results and methodological considerations. Journal of Experimental Psychology, 1969, 79 (2, Pt. 2).

Estes, W. K. Interaction of signal and background variables in visual processing. Perception \& Psychophysics, 1972, 12, 278-286.

Estes, W. K., \& Taylor, H. A. Visual detection in relation to display size and redundancy of critical elements. Perception \& Psychophysics, 1966, 1, 9-16.

Estes, W. K., \& Wessel, D. L. Reaction time in relation to display size and correctness of response in forced-choice visual signal detection. Perception \& Psychophysics, 1966, 1, 369-373.

McIntyre, C., Fox, T., \& Neale, J. Effects of noise similarity and redundancy on the information processed from brief visual displays. Perception \& Psychophysics, 1970, 7, 328-332.

Posner, M. I., \& Boies, S. J. Components of attention. Psychological Review, 1971, 78, 391-408.

Potter, M. C., \& Levy, E. J. Recognition memory for a rapid sequence of pictures. Journal of Experimental Psychology. $1969,81,10-15$.

Treisman, A. M. Strategies and models of selective attention. Psychological Review, 1969, 76, 282-299.

(Received for publication September 15, 1972; revision received January 22,1973 .) 